Borg, R., Toikka, A., \& Primmer, E. (2015). Social capital and governance: a social network analysis of forest biodiversity collaboration in Central Finland. Forest Policy and Economics, 50, 90-97.

http://dx.doi.org/10.1016/i.forpol.2014.06.008

\title{
Social Capital and Governance: a social network analysis of forest biodiversity collaboration in Central Finland
}

Abstract

Collaboration between different actors is crucial for responding to the acute need for forest biodiversity conservation. Network theories highlight the importance of information sharing, social cohesion and mutual goals that constitute social capital. We test and demonstrate how these ties relate to each other and which ones are crucial for collaboration in a government funded collaborative network for forest biodiversity and Siberian Jay conservation in Finland. Our analysis shows that the ties of trust and information exchange are mostly reciprocal. Rather than building on common goals or information exchange, trust that is built on working together constitutes strong equal and mutual connections. Using both qualitative and quantitative evidence, our analysis serves as a test for the usefulness of the technical social network analysis method in bringing depth to the understanding of collaborative network governance.

KEYWORDS: Social Networks Analysis (SNA); social capital; cooperative networks; voluntary forest conservation; non-industrial private forest

\section{Introduction}

Collaboration between different actors is generally considered crucial for developing legitimate and sustainable forest biodiversity conservation policy. Although the understanding of the importance of collaboration and social capital in conservation is growing (Pretty 2003), the knowledge about the functions of collaboration and the subsequent structure of the collaborative networks remains an important empirical challenge. In a situation where biodiversity conservation is outsourced to networks crossing levels and sectors (Jordan and Lenschow 2010, Young et al. 2012), we need to 
understand what the collaborative networks consist of and what keeps them working toward the intended goal. Network theories inform us of the importance of information sharing, social cohesion and mutual goals (Powell 1990, Rhodes, 1997, Innes and Booher 1999). Whether these are indeed the factors that the targeted government supported networks possess or have the potential to harness needs to be assessed empirically. It is important to understand how the ties of information sharing, trust and shared interests relate to each other and which ones are crucial for collaboration.

In this paper, we analyze the structure of a collaborative network that aims to advance forest biodiversity conservation in Finland in a context where the need for conservation is pressing. The traditional use of forests for timber production has until recently been in conflict with any conservation efforts and more collaborative approaches are sought for. Through this case, we test and demonstrate the usefulness of social network analysis (SNA) method in bringing depth to the understanding of state-funded collaborative network governance.

Targeted support and external resources invested in collaboration can contribute to the development of networks and accumulation of social capital (Wolf and Hufnagl-Eichiner 2007, Mandarano 2009). Information sharing is a key to advancing sustainability although it can importantly vary across the network (Crona and Bodin 2006, Wolf and HufnaglEichiner 2007; Saarikoski et al. 2012). The general postulate is that a range of forms of collaboration across public and private sector boundaries generate new potential for learning, adaptation, and social capital in sustainable natural resource management (Cashore and Vertinsky 2000, Folke et al. 2005; Fernandez-Gimenez et al. 2008). Additionally, balancing interests and increasing commitment to ecological sustainability are considered important reasons for advancing collaborative governance (Conley and Moote 2003, Primmer and Kyllönen 2006). With these optimistic expectations, collaborative governance has an important role in the mix of conservation policies (Howlett,and Rayner 2007). The need to develop collaborative governance is accentuated because of the shrinking government funds (Young et al. 2012) and the aggravating biodiversity concerns (Hooper et al 2012).

Responding to the acute need for increased forest biodiversity conservation in Finland, the Finnish government has sought for new ways of engaging the actors making decisions 
about the use of non-industrial private forests (Paloniemi and Tikka 2008; Primmer et al. 2013). These non-industrial private forests, covering two thirds of the country, are traditionally managed for timber production. In the area where non-industrial private forests dominate, the protected area coverage is as low as two percent of forest land. As a concrete way of engaging public sector and non-governmental forestry and environmental organizations as well as land-owners in a collaborative effort to conserve biodiversity, the Finnish Ministry of Agriculture and Forestry has funded projects of cooperative networks for forest conservation since 2004. The cooperative networks aim at increasing forest conservation on private lands in cooperation with a wide range of different forestry and conservation actors.

Based on earlier experiences of similar networks in Finland, the financial boost and momentum can increase the information exchange and trust among the actors (Primmer and Keinonen, 2005; Primmer 2011). Additionally, successful collaboration can mobilize the power that the actors possess or that they can accumulate together towards advancing mutual interests (Saarikoski et al., 2012). Enhancing these ties of information sharing, trust and mutual interest can contribute to the outcome of the collaborative effort. However, as the collaborative natural resource governance literature shows, the degree to which sharing information, trust and interests coincide is not well understood.

A systematic method for measuring and analyzing the ties in a network is Social Network Analysis (SNA, Hirschi 2010; Wasserman \& Faust 1994; Borgatti et al. 2009). SNA allows studying the interconnectivity of different actors in social processes. Conceptually and methodologically, SNA focuses on the relational characteristics of social phenomena as well as the subsequent behavioral patterns. SNA has been applied in natural resource management; for example in analyzing fishermen as coastal resource managers (Crona and Bodin 2006), forest owner communication in timber sales (Korhonen et al. 2012), social learning in rural planning (Larsen et al. 2011), and collaborative network structures contributing to social capital (Mandarano 2009).

In this article, we analyze the structure of a cooperative network for forest conservation utilizing SNA tools and survey data from a forest biodiversity conservation network. We use exploratory SNA to describe the network positions of individual organizations and the macro-structure emerging from organizations independently establishing contacts in the 
network. We compare three measures of network ties: information, trust and goals as well as their effects in the network.

Our research questions are (i) What kind of connections and which actors dominate the forest conservation network? (ii) In what kind of connections is information and knowledge exchanged? (III) What kind of connections foster trust in the network? (iv) What kind of shared goals form coalitions in the network? (v) How do the different types of ties coincide?

Our aim is to gain a thorough understanding of the social connections and relationships in government supported organizational networks in a setting where the history of cooperation is short and the network is seen as a new and effective way to govern forests. More generally, our analysis sheds light on how networks contribute to conservation governance.

\subsection{Forest conservation networks}

Finnish forest biodiversity policy is faced with the challenge to stop the continuous biodiversity decline whilst maintaining legitimacy among the private non-industrial owners who dominantly own those forests where the conservation void is large (Syrjänen et al. 2007; Paloniemi and Tikka 2008). To address this challenge, a number of different policy instruments have been designated under a National Forest Biodiversity Programme that runs at least until 2016 (METSO 2008). The programme and its instruments have originally been developed jointly by the Ministry of Agriculture and Forestry (MoAF) and the Ministry of the Environment (MoE) through a lengthy working group process that has included researchers, land-owners and environmental NGOs in the early 2000s. One of the instruments, financed by the Ministry of Forestry and Agriculture has channeled support to seven cooperative networks during the years 2009-2012, following a pilot during 20032007. As the results from the pilot project allowed the network organizations to find new ways to cooperate and share information (Primmer \& Keinonen 2005, Primmer 2011), the new funding also aimed at generating these types of intermediate outcomes for conservation. 
One of the seven funded networks was built around an idea to protect habitats in the last remaining territory for Siberian Jay in Central Finland. Siberian Jay is a taiga forest bird species that is increasingly endangered in its southernmost territory. The territory is fast receding north because old spruce forests are becoming fragmented by logging and land use change (Laita 2012). The Siberian Jay Network was initiated and established by the largest nature conservation NGO in Finland, the Finnish Association for Nature Conservation (FANC; Suomen Luonnonsuojeluliitto SLL) as a response to a call by the MoAF. The chairman of FANC played a key role as the leader of the network; he organized all the network meetings, field days and other activities. Hehad also participated in mapping suitable Siberian Jay territories for conservation.

The Siberian jay network received funding from November 2009 till December 2011. During its operation, the network started forest nature management projects and conserved approximately 1000 hectares of Siberian Jay forests in Central and Eastern Finland. As a concrete output, the network produced a brochure about Siberian Jay for private forest owners and a guideline for management for forestry and conservation professionals. The network joined actors that had previously not worked together for a shared goal on forest conservation, including environmental NGOs, forestry professionals and a national forest owners' advocacy organization.

\section{Collaborative governance and social capital}

Social capital is generally thought of as a key component in building and maintaining democracy (Putnam 2000). Social capital "refers to connections among individuals social networks and the norms of reciprocity and trustworthiness that arise from them" (Putnam, p. 19). This classic social capital definition, originating from Coleman (1998) defines three key components for social capital: trust or the expectation and obligations of informal relations, information channels, and norms with effective sanctions.

The conceptualization of social capital as a set of vaguely related activities have been criticized (Fischer 2005). The interpretation of social capital as participation in specific activities remains hard to justify, but the idea of social connections that a person or an organization is able to draw upon has maintained credibility in empirical tests. While community is hard to measure empirically, networks that support specific tasks can be 
singled out, which points to a network interpretation of social capital (Kadushin 2012, 164165).

As sociologists have begun to focus on social capital in networks, political scientists have started to theorize on new aspects of political decision-making. Instead of governments steering, policy is considered to require multiple actors and a broad collaborative interpretation of governance requiring networks of autonomous individuals and organizations (Rhodes 1997; Stoker 1998; Kooiman 2003).

The confluence of these two traditions is obvious, generating a solid theoretical basis for governance networks and social capital (e.g. Lowndes \& Wilson 2001). Governance networks are seen as generating political opportunity structures, possibly with governmental actions generating the structure (Maloney, Smith \& Stoker 2000). The key dilemma of governance networks is how to deal with the different interconnected goals, indeterminacy and institutional ambiguity (Hajer and Versteeg 2005). Traditional political networks are often organized around shared interests and building of advocacy coalitions (Sabatier 1998). However, more fluid governance network ties may or may not coincide with those of trust and common goals but if the ties are for mere passing information and the networks are driven by search for information. Governance networks consist of organizations that are able to freely connect to others (Rhodes 1997). These networks are not supported by power relations or legitimate punishment in the same way as hierarchical relations in democratic policy-making, and thus they need to draw upon shared social capital to reinforce network commitments.

The organization of networks to both support trust and enable political action puts social capital at the heart of collaborative governance. Indeed, these structural elements have been found to be important for collaborative policy-making and implementation in a variety of settings. For example, combining internal resources and network ties with external stimulus has been shown to contribute to sustainable collaboration in natural resource management (Mandarano 2009, Rickenbach 2009). Bridging organizations that move information between management scales and knowledge systems can lower costs and ease conflict resolution (Folke et al. 2005). Emerging urban networks have been found to disrupt natural resource managing rural networks (Maru et al. 2007) but urban governance networks can be effective when they combine tight subgroups with hubs that allow the flow 
of information to other groups (Toikka 2010). In line with the original theses of social capital and networks, communication gaps between groups have been found to impede collaborative management in marine resource governance networks (Crona and Bodin 2006, Weiss et al. 2012).

The importance of social capital is an implicit assumption in the forest biodiversity program METSO and the forest biodiversity conservation network, namely the Siberian Jay network that constitute the empirical target of our analysis. We measure how information sharing, trust and shared goals as expressions of social capital manifest in the network.

\section{Social Network Analysis}

SNA addresses empirical questions about collaborative governance and social capital in networks. Even relatively small groups of actors form complex network structures that can be discovered with SNA methods but are hard to detect otherwise as social structure is usually a mix of cohesive subgroups (Frank 1995) linked by so-called weak ties (Granovetter 1973). Weak ties link strong, tightly-knit groups together in a seemingly random and unimportant fashion that can paradoxically turn out to be the most important links in defining how the network works. For example, private forest owners can have weak links to more central actors in the network, even though their own position is peripheral (Borg and Paloniemi 2012).

SNA is not a single method, but a group of methods arising from a shared operationalization of the concept of social order: the individuals and the organizations they form are embedded in thick webs of social relations and interactions (Borgatti et al. 2009). This operationalization applies the systematic representation of networks as ties between nodes and the tools derived from mathematical graph theory to understand interesting properties of particular patterns of ties. SNA is a multi-disciplinary approach: the tools are similar for any self-organizing autonomous complex network, and the approach has been developed and tested in social psychology, sociology, and political science. Recent developments even aim to unify network approaches to physical sciences and social sciences under a general umbrella of network science (Borgatti et al. 2009). 
Thus, SNA requires a stringent definition for the nodes and ties that are included in the network. Governance settings in general and our analysis in particular has a relatively obvious set of actors who are involved. In our empirical case the organizational actors who took part in the network activities constitute the network. The definition of the ties is less straightforward, as many types of ties are in play - the definition of simple measures for network analysis has been called one of the critical challenges for policy network analysis (Scholz et al. 2008). Conceptually, a single type of tie defines a single network and when multiple types of tie are of interest, they define multiple networks consisting of the same actors.

We draw upon the policy networks tradition (Knoke et al. 1996) and later governance studies (Kooiman 2003) to define three ties or three networks within the Siberian Jay network. Following the ideas of social capital, we measure 1) the flow of information among organizations in the network, 2) inter-organizational trust, and 3) views of shared goals or interests.

The network measures used in the analyses are degree, hub and authority measures, and community search methods. Degree is simply the number of inbound links each organization has (Wasserman \& Faust 1994). Hub and authority analyses are based in algorithms developed for web links (Kleinberg 1999), but have since been used to find structure in smaller social networks as well, like company supplier networks (Borgatti \& Li 2009). A hub is an organization that is connected to many of the most central authorities, while an authority is an organization receiving traffic from the hubs. In a knowledge sharing network, an authority is the origin of the information while the hub is able to control the flow to and from the authority. Community detection is about finding connected subgroups when these groups are less than perfectly connected and less than perfectly isolated from each other. For example, there are always some differences between goals of organizations within a community, and always some overlap across communities, and these algorithms allow us to find the most prevalent structures. In this paper, an algorithm called Louvain community detection (De Meo et al. 2012) was used.

\section{Data}

\section{$\underline{4.1 \text { Preliminary questionnaire }}$}


Based on careful familiarization with the funded networks through documents, interviews and attending meetings, we developed a preliminary questionnaire and addressed it to key actors $^{1}$ in five cooperative networks in March 2010 in order to define the networks and the organizations to be included in the survey. The key actors were simply asked to list organizations and actors that they cooperated with in their respective network. The preliminary questionnaire had three rounds of listing in order to help informants remember as many actors as possible. First, they actors listed the actors that they mostly cooperated with. Second, they listed the actors that worked with the network but were less active, and third, the informants were asked to list any other actors that might not have been listed in the first two rounds. They also reported whether they shared information, trusted or had similar objectives with each of the listed actors on a five point scale where 1 signaled "I completely disagree" and 5 signaled "I completely agree".

On the basis of the four out of five returned questionnaires, we inferred that the cooperative networks were built on links of information and trust. The organizations did not necessarily share the same interests, but they possibly found promoting forest biodiversity so important that working with organizations with different interests was not a hindrance for cooperation and collaboration.

\section{$\underline{4.2 \text { Network survey }}$}

Following the structure of the preliminary questionnaire, we developed a network survey to measure the ties resting on information, trust and interests on a 5-point scale ranging between "not at all", and "mostly". The survey was sent to three networks in April 2011 with a web-based survey program Webropol. Those three networks were chosen because we received the most responses from them to the preliminary questionnaire.

Although private forest owners were listed in the preliminary questionnaire, they were not included in the target group because of the anonymity of the forest owners. All the other actors that had been identified with the preliminary questionnaire were listed in the survey and all these same actors were invited to fill in the survey. The informants were asked to

1 The key network actors were leaders of the cooperative networks or otherwise known to be active in the network. 
list and report information sharing, trust and shared interests regarding any additional actors not listed in the survey, in order to reduce the risk of informant and researcher bias. The survey was sent to 64 recipients, and we received altogether 17 responses ${ }^{2}$, which then constituted our dataset for SNA analysis. Out of the three networks, a representative response rate could be obtained only from Siberian Jay network. Responses were not received from most of the local forestry associations, rural development networks, county representatives or central union for agricultural producers and forest owners. This means that the results may be slightly biased towards other actors' experiences.

With the limited dataset, the results would not be statistically valid and generalizations could not be made to other networks. Addressing the other networks at the initial stage however allowed us to understand the general structure of the Siberian Jay network relative to the other networks, Instead, we pursued more ambitious qualitative analysis and generalized our findings against social capital theory. The Siberian Jay Network is one case of social networks around voluntary forest biodiversity conservation, and that is where generalizations arise from. Analyzed ties and connections, and what they are build on, can have more general and practical implications and in similar other social networks.

\subsection{Explorative analysis}

The ordinal 5-point measures of information, trust, and interest were analyzed with SNA software packages Pajek (de Nooy et al 2011) and Gephi (Bastian et al. 2009) with an exploratory aim to understand the three types of ties. Individual positions were evaluated for centrality (e.g., prestige or popularity) and brokerage (e.g., ability to control the flow of information). The macro-structure was analyzed to estimate centralization, center-periphery structures or the formation of dense sub-networks or cliques. We compared the network positions to organization attributes. We visualized the network to compare the connections and to highlight the interesting findings in a fashion that remained true to the data, presenting the full network and the reported relationships.

\footnotetext{
2 The resposes were received from Regional Forestry Centre of Central Finland, Regional Environment Centre (ELY), FANC, Forestry Development Centre Tapio, Birdlife Finland, two logging companies, local FANC and Birdlife associations, Finnish Hunters` Association, one local forestry association, Finnish Environment Centre, Ministry of the Environment, and Ministry of Forestry and Agriculture.
} 
First, we analyzed information exchange between the network actors, which allowed us to recognize the information channels and possible blocks in the network. Second, we analyzed trust in the network, i.e. the degree to which the actors were considered trustworthy, and the network structures that the trusting ties remaining alert to potential social cliques. Third, we analyzed the structure of the network that could be identified with shared interests, to generate an understanding of interest-based coalitions. Finally, we compared these three types of network ties, their coincidence and divergence.

\subsection{Qualitative observation supporting answering the research questions}

To back up our quantitative SNA analyses, we used material from qualitative field work that was done during 2010-2012 using action research methods (Maurer and Githens 2010) with the Siberian Jay network. This empirical work constituted participation in the network meetings and field trips, organizing workshops with the network and communicating preliminary results to the network. The researchers were not a part of the Siberian Jay Network, but rather observed the networks and facilitated communication by organizing events. The questionnaire and the survey were sent to all listed network actors even though the researchers had prior experience of some not responding to invitations. Additionally, 15 network actors were interviewed twice, first in the beginning of the network project and for the second time after it had ended. The interviews were meant to allow analyzing how actors perceived the cooperation and the network before the project and after it. Finally, altogether 20 actors participated in three focus groups that discussed private forest conservation, possible cooperation partners and willingness to conserve forests. The focus group participants were private forest owners and forestry professionals because it seemed that they were not active in the network. The qualitative observations were used in interpreting the quantitative SNA findings. We used both the explorative SNA analysis and the qualitative observation in answering the research questions we posed.

\section{$\underline{\text { 5. Results }}$}

\subsection{Network density}

The networks formed by the three types of ties were fairly sparse: the actors reported strong or very strong links in $26 \%$ ties of all possible in the knowledge relation; $36 \%$ of the 
time in the trust relation; and $30 \%$ of the time in the common goals relation. The trust and common goals relationships were rarely antagonist: less than $5 \%$ of the ties implied complete distrust or completely opposite goals. The knowledge relation included more cases where information was rarely $(15 \%)$ or never $(11 \%)$ received.

\section{$\underline{5.2 \text { Ties of information }}$}

The explorative analysis of information ties revealed smaller networks of information inside the Siberian Jay network (Figure 1). The strongest ties of information had developed between National Forest and Park Service, Regional Environment Center and the environmental NGO that ran the network (FANC). Smaller networks had also developed between different NGOs and between authorities. However, these small networks were not closed; they had connections to other actors in the network. 


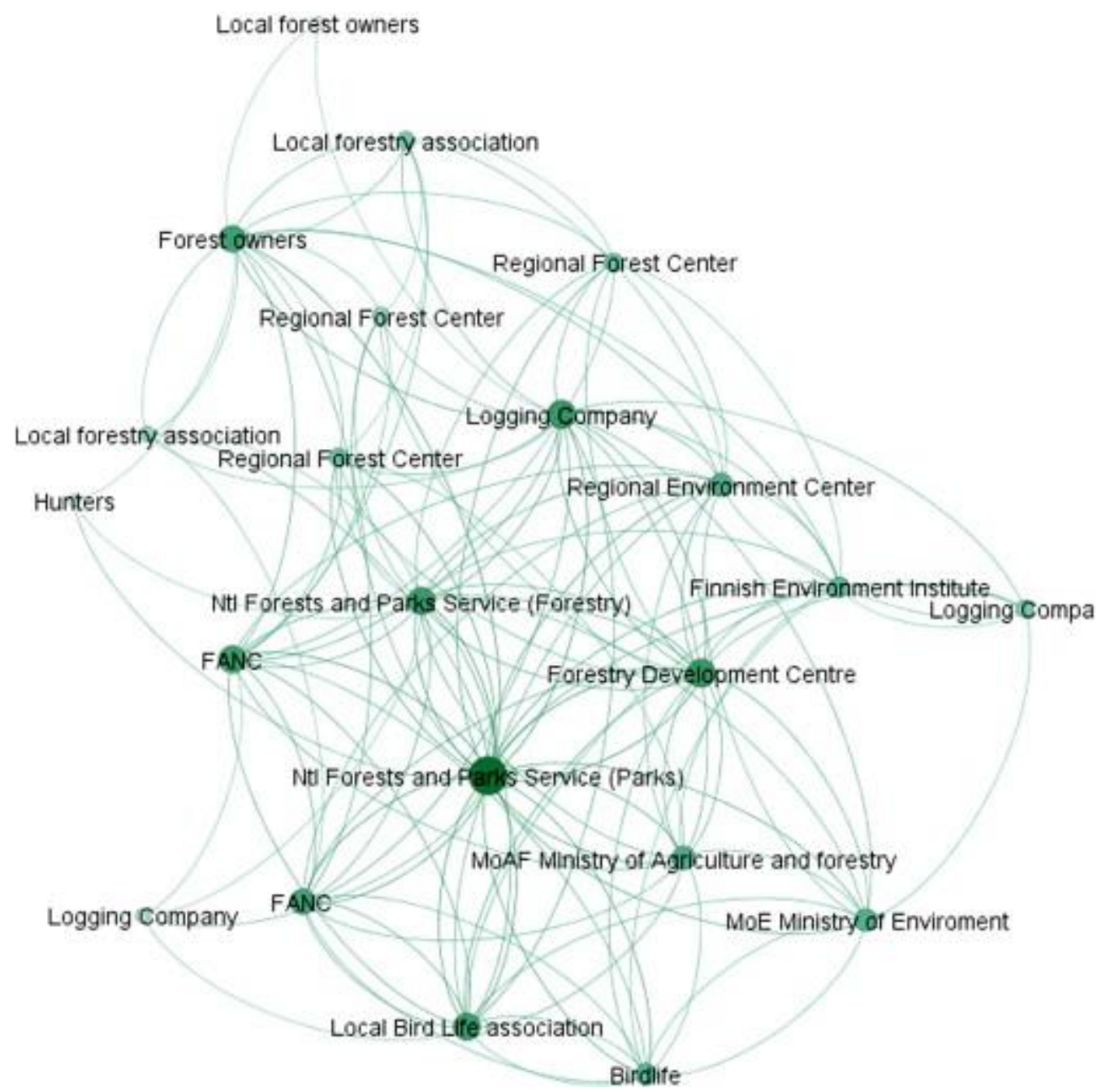

Fig. 1. Ties of information. The larger the dot is, the more reciprocal ties the actor has.

National Forest and Park Service and Regional Environment Center were seen as expert actors that also shared much information. The SNA analysis showed that these actors became hubs of information in the cooperative networks. The analysis also revealed weaknesses in information flow; the two-way connections (both obtaining and receiving information) between authorities were weaker than what the formal structure of the network organization would suggest. This may have been caused by the incompatibility of technical information systems of different public sector actors, which was often raised as an issue in the network meetings and workshops. Importantly, however, most actors had some informational ties in the network. 


\section{$\underline{5.3 \text { Ties of trust }}$}

Ties of trust were generally strong and mostly mutual. Louvain method communities of trust were found, but interestingly, there were three types of them. For example, there was a community between Regional Forestry Center and environmental actors. Furthermore, there were two forestry-oriented communities and one environmentally-oriented community, as can be seen in Figure 3.

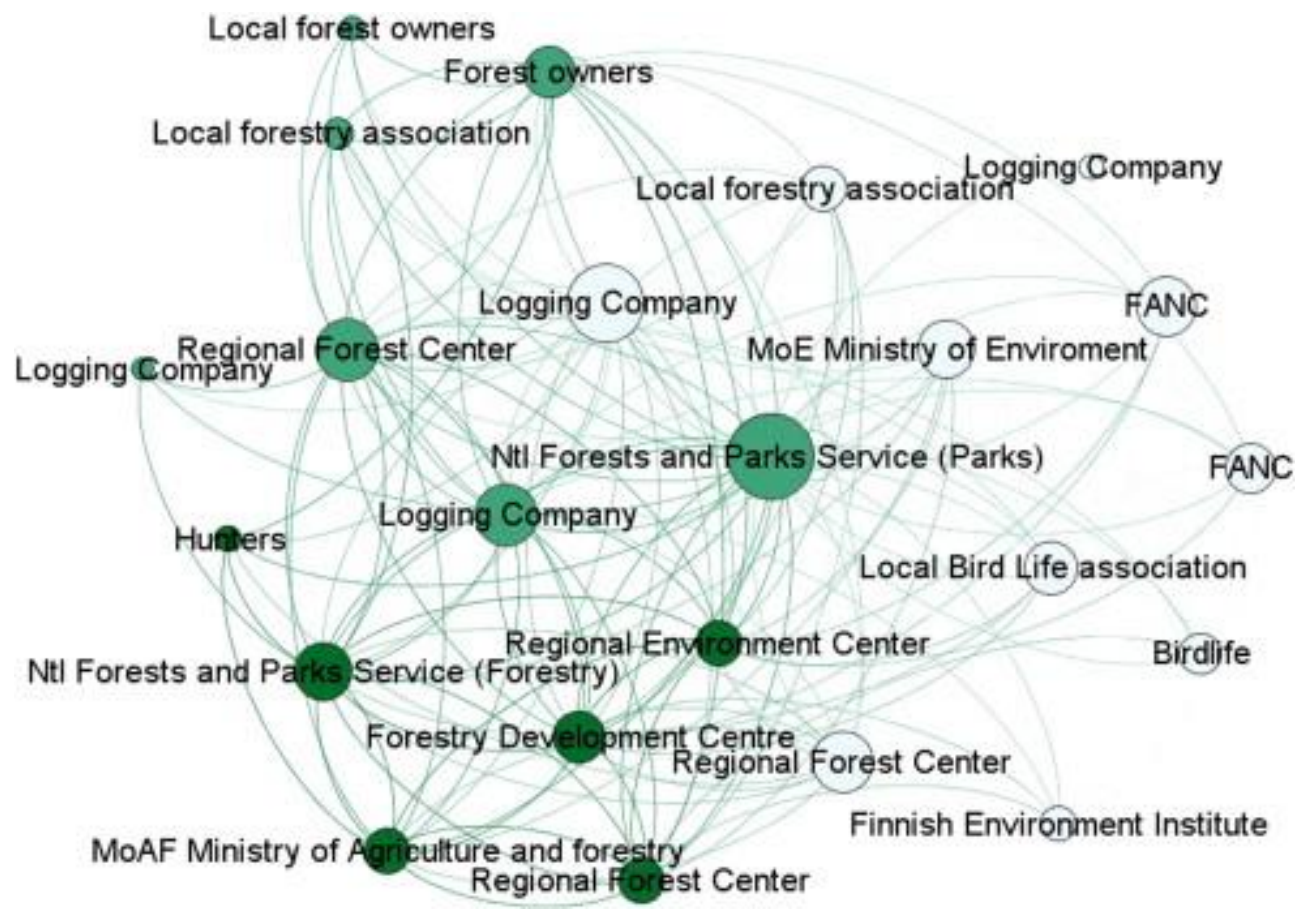

Fig. 2. Ties of trust. Actors in the communities of trust have been grouped close to each other.

Trust was built especially among like-minded actors and actors of similar position, but there were numerous ties of trust between the communities. Interestingly, there were more ties between different communities than there were within the communities.

The actors that trusted other actors the most and were trusted the most were FANC, Regional Environment Center and National Forest and Park Service. There were no actors that did not trust other actors or were not trusted. It is likely that taking part in the network required an initial level of trust of the other actors. 


\section{$\underline{5.4 \text { Ties of common goals }}$}

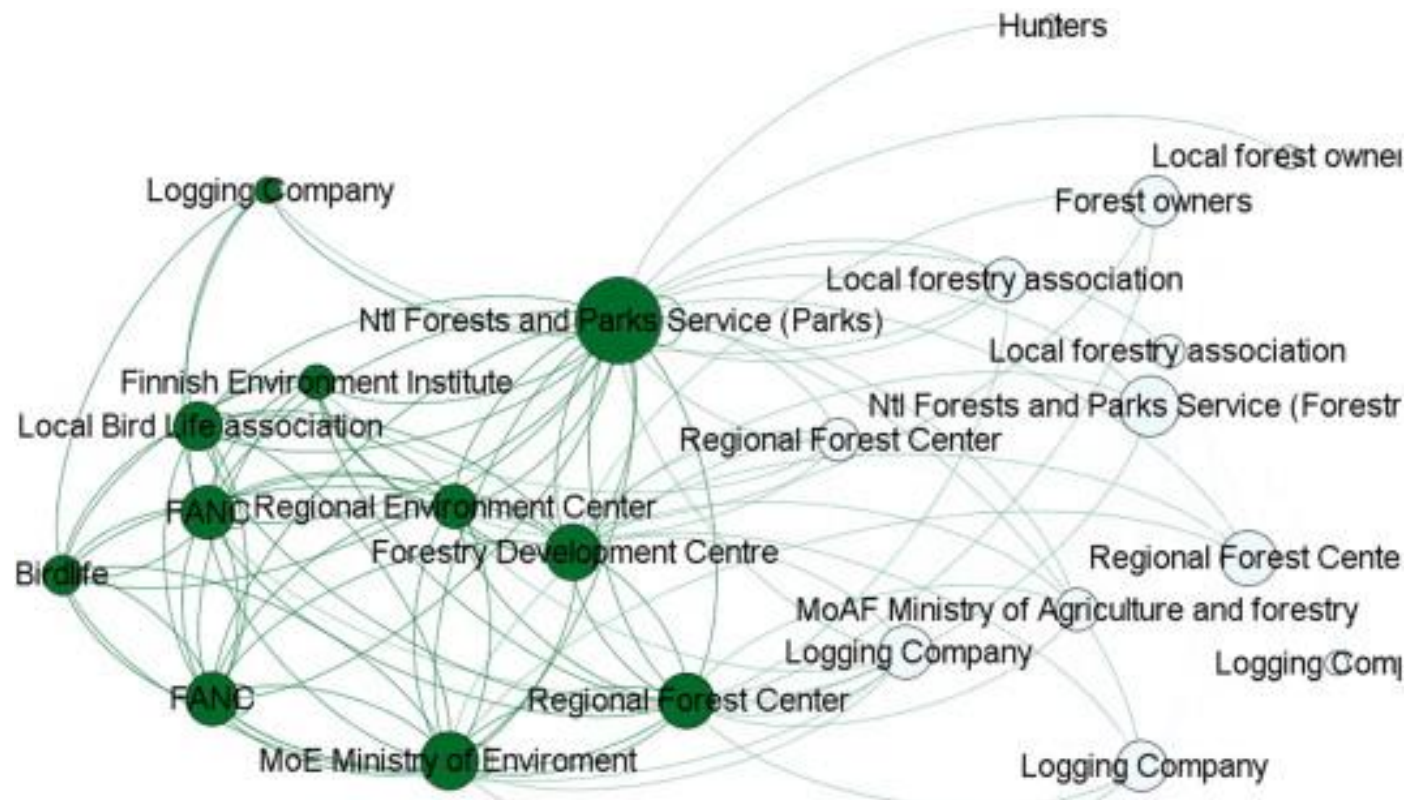

Fig. 3. Ties of common goals. Actors in the communities of common goals have been grouped close to each other.

The explorative analysis of common goals revealed that there were two communities of common goals: one among forestry actors (Regional Forestry Center, National Forest and Park Service, logging companies, Local Forest Management Associations and Ministry of Forestry and Agriculture), and another one among environmental authorities, environmental NGOs and alternative logging companies. The communities did not follow a common division between forestry and conservation. Interestingly, the Regional Forestry Center was a part of the community of the more environmentally-oriented actors, and hunters were in the community of forestry-oriented actors.

The communities were not separate; instead, they had many ties linking them. Regional Forestry Center, Regional Environmental Center, Ministry of the Environment, Forestry Development Center (Tapio) and FANC were the actors that had links of common goals across communities. All these actors were also significant actors in the network; they were referred to as having common goals with many actors. These actors evaluated themselves 
as having common goals with many other actors. Again, National Forest and Park Service stood out as a node in the network. It appears that it had a position in the network that most actors could relate to.

\section{Answers to research questions}

Looking at the connections and actors dominating the Siberian jay network, we did not find as strong a domination by forestry actors as what has been suggested in analyses of similar organizational fields in Finland (Primmer 2011; Saarikoski et al., 2012), or which was expected in this research. The forestry actors were connected, but not with the strongest links in the network. Surprisingly, National Forest and Park Service had developed into the most important information sharing actor in the network, although it does not generally engage directly with private land-owners (Wolf and Primmer, 2006). Even the qualitative fieldwork had not shown the National Forest and Park Service to be a very active actor although it was perceived to use the network as a valuable source of information and knowledge for its own organizational purposes, i.e. inventorying and distributing information on forest management and conservation. As said, perhaps it was perceived to be a neutral actor in a conservation network where actors would tend to take opposite stands.

We addressed the social capital postulates of information sharing and trust (Maru et al. 2007, Mandarano 2009; Saarioski et al., 2013) based on estimates of information flow and trust. We found that particularly trust conditioned the network. Flow of information constituted many two-way connections, differing significantly from the findings of Mandarano (2009). It is possible that the information flow is quite a technical resource flow as consultation to solve single issues or of strategic importance on a contractual basis (Wolf and Hufnagl-Eichiner, 2007; Primmer 2011). However, we found information flow concentrated around two significant organizations, National Forest and Park Service and the Regional Environment Center that played key roles in the network. They were probably evaluated by other actors as quite neutral authorities who could be given information without risking trust or own interests (Lauber et al. 2008).

Further analyzing social capital, we found that trust played a clearly more significant role in the network than information. This is probably the case in any network setting where the actors join forces for a shared cause (Innes and Booher 1999). A single actor did not stand 
out as a very trusting and trustworthy actor. Instead, all the major actors in the network trusted each other and were seen as trustworthy. The importance of trust echoes the positive tone generally attached to collaborative networks (Mandarano 2009). However, this type of externally resourced networks might avoid the loss of trust and consequent conflicts because of their limited spatial and temporal scale (Maru et al. 2007, Primmer 2011).

Table 1. Knowledge transfer and perception of common goals by trust.

Knowledge transfer often or very often $*$ high or very high trust crosstabulation $\%$ within high or very high trust

\begin{tabular}{llllllll}
\hline & & \multicolumn{6}{l}{ High or very high trust } \\
& & No trust & Trusts & $\begin{array}{l}\text { Is } \\
\text { trusted }\end{array}$ & $\begin{array}{l}\text { Trusts and is } \\
\text { trusted }\end{array}$ & Total \\
\hline $\begin{array}{l}\text { Knowledge transfer } \\
\text { often or very often }\end{array}$ & None & $86.30 \%$ & $41.20 \%$ & $41.20 \%$ & $19.80 \%$ & $57.50 \%$ \\
& Receives & $6.80 \%$ & $47.10 \%$ & $4.90 \%$ & $20.90 \%$ & $16.60 \%$ \\
& $\begin{array}{l}\text { Gives } \\
\text { Receives and }\end{array}$ & $6.80 \%$ & $4.90 \%$ & $47.10 \%$ & $20.90 \%$ & $16.60 \%$ \\
& $\begin{array}{l}\text { gives } \\
\text { Total }\end{array}$ & $100.00 \%$ & $6.90 \%$ & $38.50 \%$ & $9.30 \%$ & \\
\hline
\end{tabular}

Common goals high or very high * high or very high trust crosstabulation \% within high or very high trust

\begin{tabular}{|c|c|c|c|c|c|c|}
\hline & & \multicolumn{5}{|c|}{ High or very high trust } \\
\hline & & No trust & Trusts & Is trusted & $\begin{array}{l}\text { Trusts and is } \\
\text { trusted }\end{array}$ & Total \\
\hline \multirow[t]{4}{*}{$\begin{array}{l}\text { Common goals high } \\
\text { or very high }\end{array}$} & $\begin{array}{l}\text { No common } \\
\text { goals }\end{array}$ & $89.70 \%$ & $31.40 \%$ & $34.30 \%$ & $4.40 \%$ & $53.10 \%$ \\
\hline & $\begin{array}{l}\text { Cites common } \\
\text { goals }\end{array}$ & $4.70 \%$ & $55.90 \%$ & $5.90 \%$ & $16.50 \%$ & $16.80 \%$ \\
\hline & $\begin{array}{l}\text { Common goals } \\
\text { are cited }\end{array}$ & $4.70 \%$ & $3.90 \%$ & $52.90 \%$ & $19.80 \%$ & $16.40 \%$ \\
\hline & Common goals & $0.90 \%$ & $8.80 \%$ & $6.90 \%$ & $59.30 \%$ & $13.60 \%$ \\
\hline Total & & $100.00 \%$ & $100.00 \%$ & $100.00 \%$ & $100.00 \%$ & $100.00 \%$ \\
\hline
\end{tabular}


Analyzing coalitions of shared goals, we found that common goals conditioned strong links. Actors that had common goals were more likely to interact and connect with each other than actors that did not share goals. In total, a mutual view of common goals implied a trust relationship $85 \%$ of the time, and a knowledge relationship $71 \%$ of the time. Trust implied knowledge transfer $79 \%$ of the time. Taking into account how sparse the networks were, the overlap between the relationships was remarkably strong. Given cross-sectional data, it is not possible to quantify an argument for a causal link between the relationships, but qualitative interpretation of this network structure can have network management implications. Cooperation with many kinds of actors was encouraged and supported during the active stage of the network prior to the survey, and a less politicized routine for cooperation had likely developed, which has been shown to take place also in other type of forestry collaboration (Saarikoski et al. 2012). Connections between the coalitions may have been due to the routines. Encouraging interactions and connections between actors who do not have common goals will allow more new exchange of experiences and learning. Only this way can the new actors be engaged and the organizational boundaries crossed (Paloniemi and Tikka 2008).

Private forest owners remained outside the network's actual operations and functions, which appears to be an unresolved challenge for Finnish forest biodiversity conservation (Syrjänen et al. 2007, Paloniemi and Tikka 2008, Borg and Paloniemi 2012). The cooperative networks have not been able to establish strong and lasting connections with private forest owners so far, even though this is a stated goal (METSO 2008). Our findings, too, may have been somewhat different if private forest owners had replied to the survey. Regional Forestry Centers and Local Forest Owners' Associations may have stood out as very trustworthy actors, and ties of information might have been stronger. This is because most forest owners let forestry centers and forest owners' associations support them in managing their forests, and forest owners are usually content with their services (Hujala et al., 2007). In the case of the Siberian Jay Network, the observations and interviews indicated that above all, forest owners sought for information through the network.

\section{Conclusion}


We have analyzed information sharing, trust and shared interests that constitute social capital. Our empirical analysis of the Siberian Jay Network allows us to test the social capital assumptions in a real-world setting and to compare the role of different components of social capital through structural analysis of the network. Our results show that ties of trust and of information exchange form the most dense network structures. Common goals do not play as large a role in the network's activities as do trust and exchanging information. The analysis shows that ties of trust and information exchange are mostly reciprocal. Especially ties of trust form strong equal and mutual connections in the network. This suggests that the actors in the network have deliberately decided to trust other actors on the issue of conservation on Siberian Jay, and highlights a social commitment to conservation.

In general, neutral and public sector actors have built a high degree of trust, information exchange and sharing goals with other actors. It might be expected that the manager of the network becomes a node in the network with the highest degree of trust, information exchange and common goals but our analysis shows that this is not self-evident. The Siberian Jay network has been managed by an environmental NGO, which has not managed to overcome polarization between environmental and forestry actors positions in the past. As the NGO is a node in the network by all measures, it might have actually strengthened the network by allowing many smaller nodes to develop. The Siberian Jay network has clearly been able to use its ties efficiently, and achieved quite a lot during its lifetime.

The finding that there are more ties of trust between communities than within them suggests that trust has not built on common goals or information exchange, but on working together. Our survey was conductedat a point where the network had been working for a year, and the actors that became a node in each community were the most active actors in the network's processes and activities. Naturally, these actors had many connections and shared activities, and trust had developed in these activities.

Ties of information form a sparse network centered around two nodes. Since good flow of information between actors is very important in order to actually advance conservation, systems compatibility and development of information culture is important in cooperative networks. 
Our analysis demonstrates that not having common goals does not hinder actors from cooperating. Furthermore, it is important to notice that ties and connections form between very different actors even though there are differences in their goals. Nodes of the network are essential in building those ties by distributing information, staying in contact with all the actors and keeping the network working together. If the overall goal is well-functioning cooperative networks, networks should be given enough time to form and evolve with opportunities to build ties.

Additionally, it is important to pay attention to the inclusion of private forest owners if the legitimacy and accessibility of the program are taken seriously. Forest owners should also be included in the planning process of the cooperative network. Most importantly, networks should courageously experiment on different ways and means for forest owners to participate - representative participation will not advocate actual participation.

This type of project like cooperative networks will work actively only if there is funding from the government. The actors of the network may consult each other and start new cooperative projects more easily after the project has ended, since connections and ties between actors can last fore some time. However, there is no evidence that this type of collaboration would emerge without the external resource, suggesting that the government is an active actor facilitating collaborative biodiversity governance.

This research adds to the understanding of both formal and informal governance networks. We conclude that short-term governance networks operate on trust. Seemingly, differences in goals can be put aside for a collective good; that is, being able to cooperate and find solutions to conservation issues. Additionally, exchange and flow of information are a necessity in network functions. However, a network may be successful despite difficulties in flow of information, as our case of Siberian Jay network shows.

\section{$\underline{\text { Acknowledgements }}$}


The authors would like to thank the Finnish Ministry of Agriculture and Forestry and Maj and Thor Nessling Foundation for funding this research. The project benefited also from support from the European Union FP7 project POLICYMIX (grant agreement nr 244065). Many thanks go also to all network actors for cooperation and collaboration during research. 


\section{$\underline{\text { References }}$}

Bastian M., S. Heymann, S. and M. Jacomy, 2009. Gephi: an open source software for exploring and manipulating networks. International AAAI Conference on Weblogs and Social Media.

Bodin, Ö., and B. Crona. 2011. Barriers and opportunities in transforming to sustainable governance: the role of key individuals. In: Bodin, Ö., and C. Prell (eds.): Social Networks and Natural Resources Management. Uncovering the Social Fabric of Environmental Governance. Cambridge University Press,Cambridge, UK. Pages 75-92.

Borg R. and R. Paloniemi. 2012: Deliberation in cooperative networks for forest conservation. Journal of integrative environmental sciences. 9(3): 151-166.

Borgatti, S. P. and X. Li. 2009. On Social Network Analysis in a Supply Chain Context. Journal of Supply Chain Management, 45(2): 5-22.

Borgatti, S. P., A., Mehra, D. J., Brass and G. Labianca. 2009. Network Analysis in the Social Sciences. Science 323: 892-895.

Cashore, B. and I. Vertinsky. 2000. Policy networks and firm behaviours: Governance systems and firm reponses to external demands for sustainable forest Management. Policy Sciences 33: 1-30.

Coleman J. S. 1988. Social Capital in the Creation of Human Capital. American Journal of Sociology 94: S95-S120

Conley, A. and M.A. Moote. 2003. Evaluating Collaborative Natural Resource Management. Society and Natural Resources, 16: 371-386.

Crona, B. and Ö. Bodin 2006. What you know is who you know? Communication patterns among resource users as a prerequisite for co-management. Ecology and Society 11(2): 7. [online] URL: http://www.ecologyandsociety.org/vol11/iss2/art7/

De Meo, P., E. Ferrara, G. Fiumara, and A. Provetti. 2011. Generalized louvain method for community detection in large networks. In Proceedings of the 11th International 
Conference on Intelligent Systems Design and Applications(ISDA),pp.88-93.

de Nooy W., A. Mrvar and V. Batagelj. 2011. Exploratory Social Network Analysis With Pajek. In: Structural Analysis in the Social Sciences 34, Cambridge University Press.

Fernandez-Gimenez, M. E., H. L. Ballard, and V. E. Sturtevant. 2008. Adaptive management and social learning in collaborative and community-based monitoring: a study of five community-based forestry organizations in the western USA. Ecology and Society 13(2): 4. [online] URL: http://www.ecologyandsociety.org/vol13/iss2/art4/

Fischer, C.S. 2005. Bowling Alone: What's the score? Social Networks 27: 155-167.

Folke C., T. Hahn, P. Olsson, and J. Norberg. 2005. Adaptive governance of socialecological systems. Annual Review of Environmental Resources 30: 441-473.

Frank, K.A. 1996. Mapping interactions within and between cohesive subgroups. Social Networks 18: 93-119.

Granovetter M. 1973. The Strength of Weak Ties. American journal of sociology: 13601380.

Hajer M. and W. Versteeg. 2005. Performing governance through networks. European political science 4: 340-347.

Hirschi, C. 2010. Introduction: Applications of Social Networks Analysis. Procedia Social and Behavioral Sciences 4, 2-3.

Howlett, M. and J.Rayner. 2007. Design principles for policy mixes: cohesion and coherence in 'new governance arrangements'. Policy and Society, 26(4): 1-18.

Hooper, D. U., E. C. Adair, B. J. Cardinale, J. E. K. Byrnes, B. A. Hungate, K. L. Matulich, A. Gonzalez, J. E. Duffy, L. Gamfeldt and M. I. O'Connor. 2012. A global synthesis reveals biodiversity loss as a major driver of ecosystem change. Nature 486: 105-108.

Hujala, T., Pykäläinen, J., Tikkanen, J., 2007. Decision making among Finnish nonindustrial private forest owners: the role of professional opinion and desire to learn. Scandinavian Journal of Forest Research 22 (5), 454-463. 
Innes, J. and D. Booher. 1999. Consensus Building as Role Playing and Bricolage. Toward a Theory of Collaborative Planning. Journal of the American Planning Association 65(1): 9-25.

Jordan, A. and A. Lenschow, 2010. Policy Paper Environmental Policy Integration: a State of the Art Review. Environmental Policy and Governance 20, 147-158.

Kadushin, C. 2012. Understanding Social Networks: Theories, Concepts, and Findings. Oxford: Oxford University Press.

Kleinberg, J. M. 1999. Authoritative sources in a hyperlinked environment. Journal of the ACM (JACM), 46(5), 604-632.

Knoke, D., F.U.Pappi, J. Broadbent and Y. Tsujinaka. 1996. Comparing Policy Networks: Labor Politics in the U.S., Germany, and Japan. New York: Cambridge University Press.

Kooiman, J. (Ed.). 1993. Modern governance: new government-society interactions. SAGE Publications Limited.

Korhonen K., T. Hujala, and M. Kurttila. 2012. Reaching forest owners through their social networks in timber sales. Scandinavian Journal of Forest Research, Volume 27, Issue $1: 88-99$

Laita, A..2012. Conservation in Space. Jyväskylä Studies in Biological and Environmental Science 234 .

Larsen, S. C., M. Foulkes, C. J. Sorenson and A. Thompson. 2012. Environmental learning and the social construction of an exurban landscape in Fremont County, Colorado. Geoforum 42(1): 83-93.

Lowndes, V. and D. Wilson. 2001. Social Capital and Local Governance: Exploring the Institutional Design Variable. Political Studies 49: 629-647.

Maloney, W., G. Smith and G. Stoker. 2000. Social Capital and Urban Governance: Adding a More Contextualized 'Top-down' Perspective. Political Studies, 48(4), 802-820 
Mandarano, L. A. 2009. Social Network Analysis of Social Capital in Collaborative Planning. Society \& Natural Resources. 22:3, 245-260.

Maru, Y. T., R. R. J. McAllister and M. S. Smith 2007. Modelling community interactions and social capital dynamics: The case of regional and rural communities of AustraliaAgricultural Systems 92 (1): 179-200.

Maurer, M. and Githens R.P., 2010. Toward a reframing of action research for human resource and organization development: moving beyond problem solving and toward dialogue. Action Research 8(3): 267-292

METSO 2008. Government resolution on the forest biodiversity action programme for Southern Finland 2008-2016 (METSO). Finnish Government. http://www.mmm.fi/attachments/metsat/5xO83061Y/METSO Resolution 2008-

2016 ENGL.pdf (accessed 9th January 2013)

Paloniemi, R. and P.M. Tikka, 2008. Ecological and social aspects of biodiversity conservation on private lands. Environmental Science and Policy 336-346.

Powell, W. W. 1990. Neither market nor hierarchy: network forms of organization. In Research in Organizational Behavior, eds. B. Staw and L. L. Cummings, 12:295-336. Greenwich, CT: JAI.

Pretty, J. 2003. Social Capital and the Collective Management of Resources. Science 302 (5652):1912-191.

Primmer, E. and E. Keinonen. 2005. Yhteistoimintaverkostot. Suomen Ympäristö 45/2006.

Primmer, E. and S. Kyllönen. 2006. Goals for Public Participation Implied by Sustainable Development, and the Preparatory Process of the Finnish National Forest Programme. Forest Policy and Economics. 8(8) 838-853.

Primmer, E. 2011. Policy, project and operational networks: channels and conduits for learning in forest biodiversity conservation. Forest Policy and Economics, 13(2):132-142. 
Primmer, E., R. Paloniemi, J. Similä and D. Barton. 2013. Evolution in Finland's forest biodiversity conservation payments and the institutional constraints on establishing new policy. Society \& Natural Resources. 26(10), 1137-1154. .

Putnam, R.D. 2000. Bowling Alone: The Collapse and Revival of American Community. NewYork:Simon\&Schuster.

Rhodes, R. A. W..1997. Understanding governance: policy networks, governance, reflexivity and accountability. Philadelphia, PA, US. Open University Press.

Rickenbach, M., 2009. Serving members and reaching others: The performance and social networks of a landowner cooperative. Forest Policy and Economics, 11(8).

Saarikoski, H., M. Åkerman and E. Primmer. 2012. The Challenge of Governance in Regional Forest Planning: An Analysis of Participatory Forest Program Processes in Finland. Society \& Natural Resources, 25:7, 667-682.

Sabatier, P.A. (ed.) 1988. An Advocacy Coalition Framework of Policy Change and the role of Policy-Oriented Learning Therein. Policy Sciences. 21, 129-68.

Scholz J. T., R. Berardo and B. Kile. 2008. Do Networks Solve Collective Action Problems? Credibility, Search, and Collaboration. The Journal of Politics 79: 393-406.

Stoker, G. 1998. Governance as theory: five propositions. International social science journal, 50(155):17-28.

Syrjänen, K., P. Horne, T. Koskela and H. Kumela (eds.). 2007. METSOn seuranta ja arviointi. Etelä-Suomen metsien monimuotoisuusohjelman seurannan ja arvioinnin loppuraportti. Vammala: MMM, YM, Metla, SYKE.

Toikka A. 2010. Exploring the composition of communication networks of governance-a case study on local environmental policy in Helsinki, Finland. Environmental Policy and Governance, 20(2): 135-145.

Wasserman S. and K. Faust. 1994. Social Network Analysis. Methods and Applications. Cambridge: Cambridge University Press. 
Weiss K., M. Hamann, M. Kinney, H. Marsh. 2012. Knowledge exchange and policy influence in a marine resource governance network. Global Environmental Change 22: 178-188.

Wolf, S.A. and E. Primmer. 2006. Between incentives and action: A Pilot Study of Biodiversity Conservation Competencies for Multifunctional Forest Management in Finland. Society \& Natural Resources. 19(9): 845-861.

Wolf, S. A. and S. Hufnagl-Eichiner. 2007. External Resources and Development of Forest Landowner Collaboratives. Society \& Natural Resources, 20(8): 675 - 688.

Young, J.C., J. R. A. Butler, A. Jordan and A. D. Watt. 2012. Less government intervention in biodiversity management: risks and opportunities. Biodiversity and Conservation 21: 1095-1100. 